\title{
Assessment of Seasonal Variations of Average Traffic Pollution Levels in Curbside Open-Air Microenvironments in Kolkata, India
}

\author{
Anirban Kundu Chowdhury, ${ }^{1, *}$ Anupam Debsarkar, and Shibnath Chakrabarty ${ }^{1}$ \\ ${ }^{1}$ Department of Civil Engineering, Jadavpur University, Kolkata, India \\ *Corresponding author: Anirban Kundu Chowdhury, Department of Civil Engineering, Jadavpur University, Kolkata, 700032, India. Tel: +91-9433263939, E-mail: anikc13@yahoo.co.in
} Received 2015 September 16; Revised 2015 October 3; Accepted 2015 November 5.

\begin{abstract}
Background: Traffic is a source of both noise and air pollution, contributing more than $50 \%$ of the total environmental noise and air pollution load of urban areas.

Objectives: The objective of the research was evaluation of seasonal variations of the average traffic pollution level (ATPL) in terms of traffic noise and concentrations of $\mathrm{PM}_{2.5}$ and $\mathrm{NO}_{2}$ in curbside open-air microenvironments in Kolkata, India.

Materials and Methods: Number of total motorized vehicles (TMV) traffic noise, and $\mathrm{PM}_{2.5}$ and $\mathrm{NO}_{2}$ concentrations were monitored repeatedly in the microenvironments of 21 major roads between 08:00 a.m. and 08:00 p.m. in the post-monsoon (winter) and premonsoon (summer) seasons. Simultaneous data on air temperature, relative humidity, and wind speed were collected from a roof-top automated weather monitoring station. The exceedance factor (EF) was calculated for traffic noise level and concentrations of $\mathrm{PM}_{2.5}$ and $\mathrm{NO}_{2}$. The average exceedance factor (AEF) was calculated to determine ATPL of the microenvironments in terms of traffic noise level and air pollutant concentrations. Interseasonal variations between the same variables were assessed with post-monsoon to pre-monsoon (W/S) ratio and correlation analysis.

Results: ATPL was 3.35 times higher in the post-monsoon and 1.83 times higher in the pre-monsoon season than the permissible limits prescribed by the central pollution control board of India with respect to traffic noise level and $\mathrm{PM}_{2.5}$ and $\mathrm{NO}_{2}$ concentrations. W/S ratio and interseasonal correlation were 1.03 and 0.95 , respectively, for TMV; 1.00 and 0.68 for traffic noise level; 2.40 and -0.11 for PM 2.5 concentration; 1.74 and 0.19 for $\mathrm{NO}_{2}$ concentration; and 1.92 and 0.01 for AEF.

Conclusions: ATPL was higher in the post-monsoon season. W/S ratio and correlation analysis revealed interseasonal homogeneity of TMV and traffic noise levels and interseasonal heterogeneity of air pollutant concentrations and ATPL in the city microenvironments.
\end{abstract}

Keywords: Traffic, Noise pollution, Correlation, Air pollution

\section{Background}

Noise and air pollutants have different modes of transport, half-lives, measurements, origins, and mechanisms of effect on human health (1-9). Traffic is a shared source of noise and air pollution, and it contributes more than $50 \%$ of the total environmental noise and air pollution load of urban areas (10-14). Health effects including cardiovascular, respiratory, and neurobehavioral diseases have been associated with both traffic noise and air pollution exposure $(3,15,16)$. High traffic volume, traffic noise, and high concentrations of air pollutants may occur in curbside open-air microenvironments, and people are frequently exposed to the polluted microenvironments due to their occupational activities. For these reasons, a uniform methodology is necessary to evaluate average noise and air pollution levels of the microenvironments in urban areas. Vehicular pollution levels in terms of Noise-Air pollution have been studied extensively in the cities of Viana do Castelo, Portugal, and Kolkata $(17,18)$.

\section{Objectives}

The objective of the current research was evaluation of seasonal variations of average traffic pollution level (ATPL) in terms of traffic noise and concentrations of $\mathrm{PM}_{2.5}$ and $\mathrm{NO}_{2}$ in curbside open-air microenvironments in Kolkata, India.

\section{Materials and Methods}

\subsection{The Study Area}

Kolkata is the capital of the state of West Bengal, India, and is also one of the country's most populous and polluted cities (18-20). The city is bounded to the west and north-west by the Hooghly River and has a tropical savannah climate with a marked monsoon season (21). The city is divided into five major geographical regions: east, west, north, south, and central Kolkata. There is little demarcation between areas used for residential, industrial, and commercial activities. The land under 
the Kolkata Municipal Corporation covers an area of 187 $\mathrm{km}^{2}$. The study area comprised four important traffic intersections of south Kolkata: Park Street $\left(22^{\circ} 33^{\prime} 17.23^{\prime \prime} \mathrm{N}\right.$,

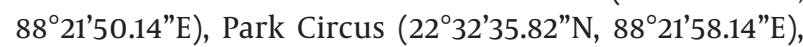
Garia (22 $\left.27^{\prime} 57.08^{\prime} \mathrm{N}, 88^{\circ} 22^{\prime} 40.10^{\prime \prime} \mathrm{E}\right)$, and the Tollygunge. Tram Depot $\left(22^{\circ} 29^{\prime} 35.10^{\prime \prime N}, 88^{\circ} 20^{\prime} 43.04\right.$ "E). A total of 38 monitoring sites were chosen on 21 major roads within the study area. The roads had minimum, maximum, and average widths of $7 \mathrm{~m}, 31 \mathrm{~m}$, and $18.50 \pm 6.40 \mathrm{~m}$ respectively. Selection of monitoring sites was limited to those within a maximum commuting time of $30 \mathrm{~min}$ from Jadavpur University (Figure 1).

\subsection{Comprehensive Plan for Data Collection}

Primary data on variables were collected according to the following monitoring program. Number of total motorized vehicles (TMV), traffic noise, and concentrations of $\mathrm{PM}_{2.5}$ and $\mathrm{NO}_{2}$ were monitored for 4 hours at the curbside open-air microenvironments of 38 sites within the study area. Simultaneous data on air temperature, relative humidity, and wind speed were recorded from a roof-top automated weather monitoring station (WM250, Envirotech) at the Jadavpur University campus. At each monitoring site, three consecutive 4 hours monitoring sessions were performed over two different consecutive week days. On the first day the monitoring was performed between 04:00 p.m. and 08:00 p.m., and on the second day the monitoring was performed between 08:00 a.m. and 12:00 noon and between 12:00 noon and 04:00 p.m. The three consecutive 4 hours monitoring sessions were repeated in the pre-monsoon season (summer) of the year 2012 (March 2012 - May 2012) and 2013 (March 2013 - May 2013) and post-monsoon season (winter) of the year 2011 - 2012 (November 2011 - February 2012) and 2012 - 2013 (November 2012 - February 2013). Finally, 12 hours time-weighted averages (TWA) for all variables were determined from each set of three 4 hours hour monitoring sessions. Thus, a total of 38 sets of data (a pre-monsoon and post-monsoon 12 hours average at each site) were generated for each variable.

\subsection{Monitoring of TMV}

TMV was determined by analysis of 15 min of video footage taken once each hour with a digital camera (DSCW150, Sony). Motorized vehicles passing through the section of the road observed by the digital camera were counted manually, and hourly motorized traffic volume was determined using a multiplication factor of 4 . Finally, TMV for $4 \mathrm{~h}$ was determined by adding the 1 hours motorized traffic volumes.

\subsection{Monitoring of Traffic Noise and Concentrations of PM2.5 and NO2}

Traffic noise level was determined with a Type II sound level meter (SC160, CESVA) under fast operation mode and in terms of A-weighted equivalent noise level. The concentration of $\mathrm{PM}_{2.5}$ was determined with a laser photometer (AM510, TSI). Both instruments were calibrated prior to each monitoring session, and data was logged with $1 \mathrm{sec}$ resolution. The concentration of $\mathrm{NO}_{2}$ was estimated as per the modified Jacob and Hochheiser (Na-Arsenite) method by using a personal sampling pump (SP330, TSI) fitted with a gaseous sampling attachment (APM411, Envirotech). All the instruments were placed parallel to each other on the sidewalk $1 \mathrm{~m}$ from the front wall of buildings. The inlets of the air samplers and the microphone were placed $1.5 \mathrm{~m}$ above ground level. Any kind of monitoring was stringently avoided in areas of construction and on rainy days during the monsoon season.

\subsection{Calculation of Exceedance Factor (EF) and Average Exceedance Factor (AEF)}

The exceedance factor (EF) was calculated to describe noise and air pollution levels of the microenvironments. The average exceedance factor (AEF) was calculated to determine ATPL in terms of noise and concentrations of the air pollutants. EF and AEF were determined with the following equations:

$$
\mathrm{EF}=\frac{C_{0}}{C_{l}}
$$

$$
\mathrm{AEF}=\frac{1}{N} \sum_{i=1}^{N} \mathrm{EF}_{i}
$$

Where, $\mathrm{C}_{\mathrm{o}}$ is the observed traffic noise level or concentration of $\mathrm{PM}_{2.5}$ or $\mathrm{NO}_{2}$ and $\mathrm{C}_{\mathrm{l}}$ is the legal limit of traffic noise level or concentration of $\mathrm{PM}_{2.5}$ or $\mathrm{NO}_{2}$. The legal limits for commercial areas prescribed by the central pollution control board (CPCB) of India $(22,23)$ were used: daytime traffic noise level, $65 \mathrm{~dB}(\mathrm{~A}) ; \mathrm{M}_{2.5}$ concentration, $60 \mu \mathrm{g} / \mathrm{m}^{3}$ (24 h TWA); and $\mathrm{NO}_{2}$ concentration, $80 \mu \mathrm{g} / \mathrm{m}^{3}$ (24 h TWA). $\mathrm{EF}_{\mathrm{i}}$ is the exceedance factor of the $\mathrm{i}^{\text {th }}$ pollutant. $\mathrm{N}$ is the number of pollutants. An EF and AEF of 1 may be considered the threshold limit of a pollutant or a group of pollutants.

\subsection{Interseasonal Comparisons of TMV, Traffic Noise, Concentrations of Air Pollutants, and ATPL}

Interseasonal comparisons of TMV, traffic noise, air pollutant concentrations, and ATPL were made through post-monsoon to pre-monsoon (W/S) ratio and correlation analysis. Correlation analysis was performed in the SPSS v20 environment. The correlation between a pair of variables was determined in terms of Pearson's correlation coefficients. Correlation analysis was also performed to investigate the effect of seasonal variations of air temperature, relative humidity, and wind speed on AEF and ATPL in the city microenvironments. 
Kundu Chowdhury A et al.

\section{Results and Discussion}

\subsection{EF of Traffic Noise and Concentrations of Air Pollutants}

Average EF for traffic noise level (EF-Leq) was $1.20 \pm 0.03$ in the post-monsoon and $1.19 \pm 0.03$ in the pre-monsoon season (Figure 2). An EF of $>1$ indicates that the traffic noise level was in excess of the daytime commercial area standard prescribed by the CPCB in both seasons. Traffic noise levels greater than the prescribed standard in Indian cities has been reported by a number of researchers (24-27). The average EF for $\mathrm{PM}_{2.5}$ concentration $\left(\mathrm{EF}^{\mathrm{P}} \mathrm{PM}_{2.5}\right.$ ) was $7.34 \pm 1.74$ post-monsoon and $3.35 \pm 0.89$ pre-monsoon. An EF of $>1$ indicates that the $\mathrm{PM}_{2.5}$ concentration was also higher than the standard prescribed by the $\mathrm{CPCB}$ in both seasons. Concentrations of $\mathrm{PM}_{2.5}$ higher than the prescribed standard in Indian cities has also been reported by a number of researchers (28-30). The average EF for $\mathrm{NO}_{2}$ concentration $\left(\mathrm{EF}_{-} \mathrm{NO}_{2}\right)$ was $1.50 \pm 0.43$ post-monsoon and $0.95 \pm 0.0 .29$ pre-monsoon. The measured concentration of $\mathrm{NO}_{2}$ was within the standard prescribed by the СРCB at $7.89 \%$ of the sampling sites in the post-monsoon season and at $65.79 \%$ of sites in the pre-monsoon season.

\subsection{AEF of Traffic Noise and Concentrations of Air Pollutants}

Average AEF was $3.35 \pm 0.67$ in the post-monsoon and $1.83 \pm 0.37$ in the pre-monsoon season, indicating that ATPL in terms of traffic noise and air pollutant concentrations was 3.35 times higher post-monsoon and 1.83 times higher pre-monsoon than the permissible limits. Similar seasonal variations in combined Noise-Air quality have been reported in Kolkata by Chowdhury et al. (31).

\subsection{W/S ratio and Interseasonal Correlation Between TMV, Traffic Noise, PM2.5 and NO2 Concentrations, and AEF}

Average $\mathrm{W} / \mathrm{S}$ ratios of TMV in $4 \mathrm{~h}$ and traffic noise (Leq) were $1.03 \pm 0.11$ and $1.00 \pm 0.02$, respectively (Figure 3). Very strong $(0.95 ; \mathrm{P}<0.01)$ interseasonal correlation was found for TMV and strong $(0.68 ; \mathrm{P}<0.01)$ interseasonal correlation was found for traffic noise. A W/S ratio of 1 and strong positive interseasonal correlation of a variable might be attributed to interseasonal homogeneity of the variable; that is, almost constant traffic volume and noise in both seasons. Almost constant motorized traffic noise in the presence of almost constant traffic volume in both seasons might also be attributed to the lower influence of air temperature, relative humidity, and wind speed on traffic noise within the urban microenvironment (32). Comparable post-monsoon (winter) and pre-monsoon (summer) traffic noise levels have been reported in the city of Jammu by Kaushal et al. (33). In contrast, a higher average $\mathrm{W} / \mathrm{S}$ ratio of the concentra- tions of $\mathrm{PM}_{2.5}(2.40 \pm 1.14)$ and $\mathrm{NO}_{2}(1.74 \pm 0.76)$ and poor interseasonal correlation between these variables indicates interseasonal heterogeneity of air pollution levels, with a higher air pollution level in the post-monsoon season. Higher post-monsoon (winter) air pollution levels in Indian cities have been reported by a number of researchers (28, 34-36). Higher post-monsoon air pollution might be attributed to lower wind speed and lower atmospheric turbulence, resulting in reduced dispersion of air pollutants. The argument of lower wind speed is supported by a lower average W/S ratio of 0.50 \pm 0.20 for wind speed; evidence for poor dispersion of air pollutants is seen in the higher standard deviation of the EFs of the air pollutants in the post-monsoon season. The average $\mathrm{W} / \mathrm{S}$ ratios of air temperature and relative humidity were $0.71 \pm 0.12$ and $1.10 \pm 0.38$, respectively. The average $\mathrm{W} / \mathrm{S}$ ratio of AEF implies that the ATPL of the microenvironments was $1.92 \pm 0.63$ times higher in the post-monsoon season, and interseasonal correlation of AEF was also found to be very weak. Therefore, ATPL also showed interseasonal heterogeneity in spite of constant traffic volume.

\subsection{Seasonal Relationship of AEF With Air Temperature, Relative Humidity, and Wind Speed}

Correlation analysis between AEF for air temperature, relative humidity, and wind speed revealed that in the post-monsoon season, air temperature had a moderately negative and statistically significant $(-0.50 ; \mathrm{P}<0.01)$ correlation with AEF (Figure 4). This might be attributed to occurrence of higher ATPL with lower atmospheric temperature. In this condition temperature inversion driven stable atmosphere in the early morning and late evening monitoring hours. In the early morning and late evening hours temperature inversion also may occur which results in a stable atmosphere that hinders the dispersion of air pollutants an increase in traffic noise level close to the road due to lower pavement temperature has been reported by Anfosso-Ledee et al. (37) and Bueno et al. (38). Correlations between AEF and relative humidity and between AEF and wind speed were statistically insignificant for the post-monsoon season.

In contrast, a moderate degree of negative and statistically significant $(-0.38 ; \mathrm{P}<0.05)$ correlation was seen between AEF and wind speed in the pre-monsoon season, which might be attributed to lower ATPL in high-wind hours due to the mixing and dispersion of air pollutants in a higher volume of air. Wind-driven atmospheric turbulence may also scatter sound unpredictably, resulting in a reduction in traffic noise level close to the road (39). This is likely the reason that in spite of almost constant traffic volume in both seasons, lower ATPL was recorded in the pre-monsoon season. Correlations between AEF and relative humidity and between AEF and air temperature were statistically insignificant for the post-monsoon season. 


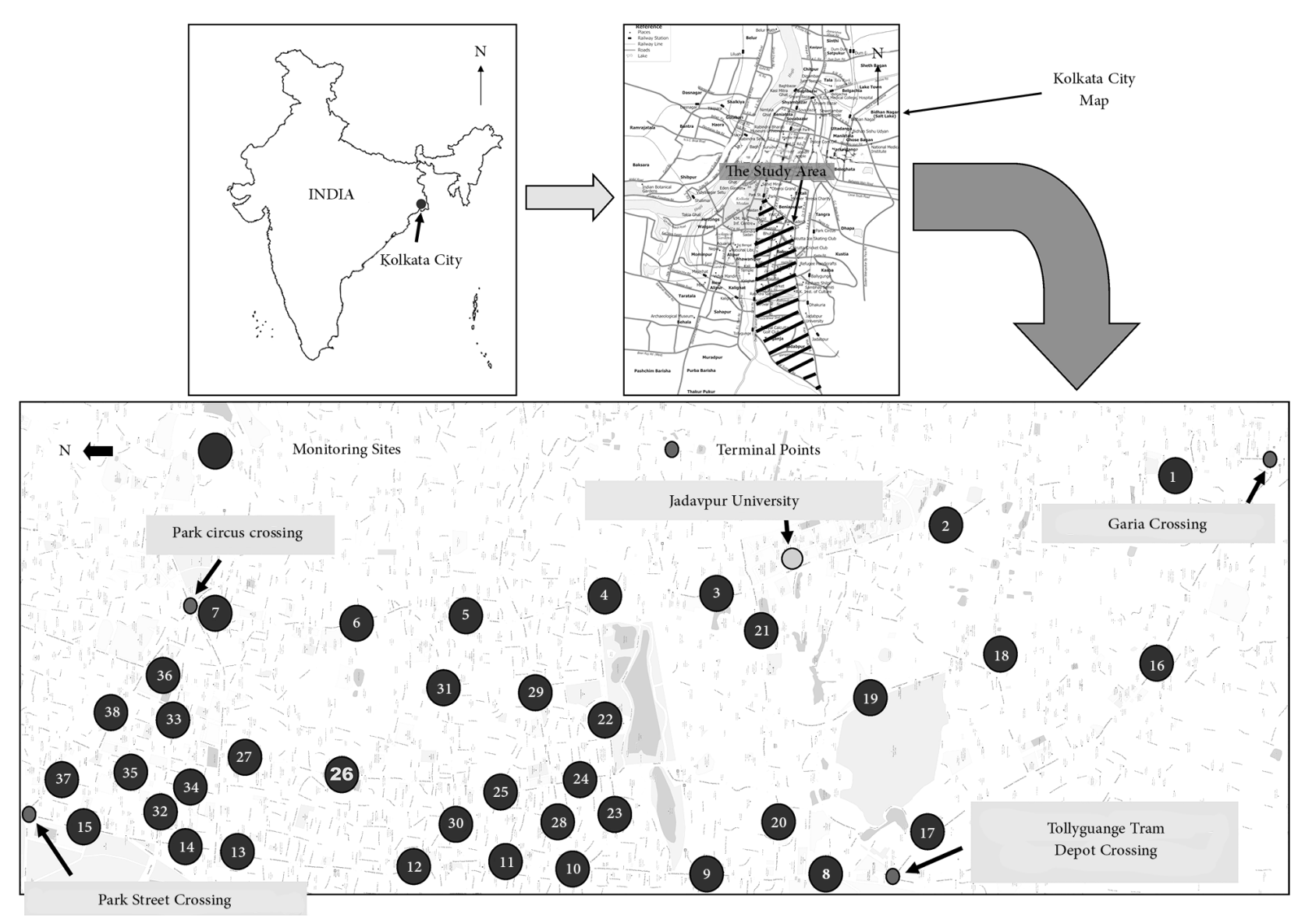

Figure 1. Study Area and Sampling Sites for Traffic Volume, Traffic Noise, and Air Pollution Survey

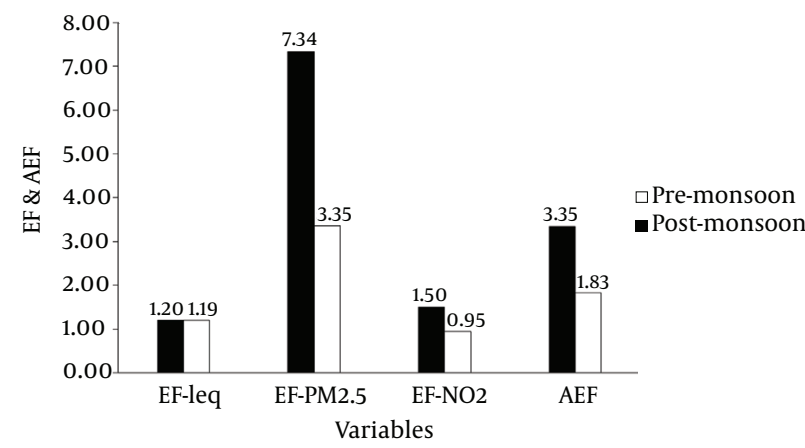

Figure 2. Seasonal Variation of AEF and EF of Traffic Noise and Concentrations of $\mathrm{PM}_{2.5}$ and $\mathrm{NO}_{2}$

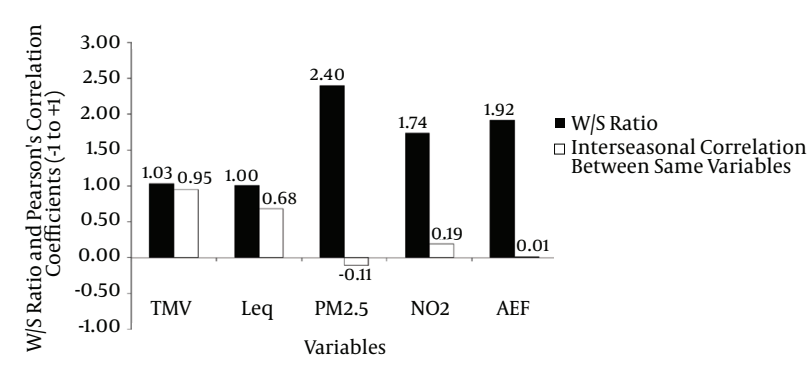

Figure 3. Post-Monsoon to Pre-Monsoon $(\mathrm{W} / \mathrm{S})$ Ratio and Interseasonal Correlation of TMV, Traffic Noise, $\mathrm{PM}_{2.5}$ and $\mathrm{NO}_{2}$ Concentrations, and AEF 
Kundu Chowdhury A et al.

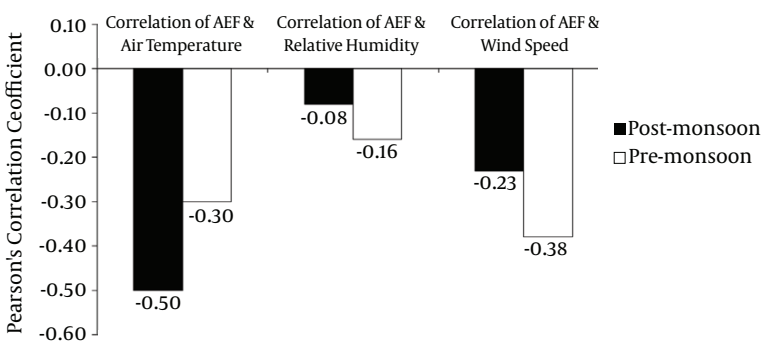

Figure 4. Seasonal Effect of Air Temperature, Relative Humidity, and Wind Speed on AEF

\section{Conclusion}

Assessment of ATPL in terms of traffic noise and concentrations of $\mathrm{PM}_{2.5}$ and $\mathrm{NO}_{2}$ revealed that ATPL was on average 3.35 times higher in the post-monsoon and 1.83 times higher in the pre-monsoon season than the permissible limits prescribed by the CPCB. W/S ratio and correlation analysis revealed interseasonal homogeneity of traffic volume and traffic noise and interseasonal heterogeneity of concentrations of the air pollutants and ATPL in the city microenvironments.

\section{Acknowledgments}

The authors are grateful to Mr. Nakibul Hossain Mondal, Mr. Nasim Mondal, and Arif Hossain Mondal, Project Staff of the DST PURSE Programme, for their active participation during traffic, noise, air pollution, and weather monitoring.

\section{Footnotes}

Authors' Contribution:Anirban Kundu Chowdhury analyzed the data statistically (which was collected during the traffic, noise, air pollution and weather monitoring), prepared the manuscript. Anupam Debsarkar and Shibnath Chakrabarty supervised the research work.

Funding/Support:The research was funded by the DST PURSE programme and a university grants commission research fellowship in science for meritorious students.

\section{References}

1. Passchier-Vermeer W, Passchier WF. Noise Exposure and Public Health. Environ Health Persp. 2000;108(s1):123-31. doi: 10.1289/ ehp.00108s1123.

2. Brook RD, Franklin B, Cascio W, Hong Y, Howard G, Lipsett M, et al Air pollution and cardiovascular disease: a statement for healthcare professionals from the Expert Panel on Population and Prevention Science of the American Heart Association. Circulation. 2004;109(21):2655-71. doi: 10.1161/01.CIR.0000128587.30041.C8. [PubMed: 15173049]

3. Ising $\mathrm{H}$, Lange-Asschenfeldt $\mathrm{H}$, Moriske HJ, Born J, Eilts M. Low frequency noise and stress: bronchitis and cortisol in children exposed chronically to traffic noise and exhaust fumes. Noise Health. 2004;6(23):21-8. [PubMed: 15273021]
4. Lusk SL, Gillespie B, Hagerty BM, Ziemba RA. Acute effects of noise on blood pressure and heart rate. Arch Environ Health. 2004;59(8):392-9. doi: 10.3200/AEOH.59.8.392-399. [PubMed: 16268115]

5. Oberdorster G, Sharp Z, Atudorei V, Elder A, Gelein R, Kreyling W, et al. Translocation of inhaled ultrafine particles to the brain. InhalToxicol.2004;16(6-7):437-45.doi:10.1080/08958370490439597. [PubMed: 15204759]

6. Elder A, Gelein R, Silva V, Feikert T, Opanashuk L, Carter J, et al. Translocation of inhaled ultrafine manganese oxide particles to the central nervous system. Environ Health Perspect. 2006;114(8):1172-8. [PubMed:16882521]

7. Leon Bluhm G, Berglind N, Nordling E, Rosenlund M. Road traffic noise and hypertension. Occup Environ Med. 2007;64(2):122-6. doi:10.1136/oem.2005.025866. [PubMed:17053022]

8. Sunyer J. The neurological effects of air pollution in children. Eur Respir J. 2008;32(3):535-7. doi: 10.1183/09031936.00073708. [PubMed: 18757691]

9. Davies HW, Vlaanderen JJ, Henderson SB, Brauer M. Correlation between co-exposures to noise and air pollution from traffic sources. Occup Environ Med. 2009;66(5):347-50. doi: 10.1136/ oem.2008.041764. [PubMed:19017692]

10. Jamrah A, Al-Omari A, Sharabi R. Evaluation of traffic noise pollution in Amman, Jordan. Environ Monit Assess. 2006;120(1-3):499525. doi:10.1007/s10661-005-9077-5. [PubMed:16741795]

11. Martín MA, Tarrero A, González J, Machimbarrena M. Exposure-effect relationships between road traffic noise annoyance and noise cost valuations in Valladolid, Spain. Appl Acoustics. 2006;67(10):945-58. doi:10.1016/j.apacoust.2006.01.004.

12. Omidvari M, Nouri J. Effects of noise pollution on traffic policemen. Int J Environ Res. 2010;3(4):645-52.

13. Ghose MK. Air pollution in the city of Kolkata: health effects due to chronic exposure. Environ Qual Manag. 2009;19(2):53-70.

14. Majumdar BK, Dutta A, Chakrabarty S, Ray S. Assessment of vehicular pollution in Kolkata, India, using CALINE 4 model. Environ Monit Assess. 2010;170(1-4):33-43. doi: 10.1007/s10661-009-1212-2. [PubMed:19894132]

15. Freire C, Ramos R, Puertas R, Lopez-Espinosa MJ, Julvez J, Aguilera I, et al. Association of traffic-related air pollution with cognitive development in children. J Epidemiol Community Health. 2010;64(3):223-8. doi:10.1136/jech.2008.084574. [PubMed: 19679705]

16. Gan WQ, Davies HW, Koehoorn M, Brauer M. Association of long-term exposure to community noise and traffic-related air pollution with coronary heart disease mortality. Am J Epidemiol. 2012;175(9):898-906. doi: 10.1093/aje/kwr424. [PubMed: 22491084]

17. Silva LT, Mendes JFG. City Noise-Air: An environmental quality index for cities. Sustain Cities Soc. 2012;4:1-11. doi: 10.1016/j. SCS.2012.03.001.

18. Chowdhury AK, Debsarkar A, Chakrabarty S. Seasonal variation of noise-air quality and state of exposure to noise-air pollution at curbside open-air microenvironment of kolkata city, india. Int J. 2015;3(1):16-30.

19. Karar K, Gupta AK, Kumar A, Biswas AK. Seasonal variations of PM10 and TSP in residential and industrial sites in an urban area of Kolkata, India. Environ Monit Assess. 2006;118(1-3):369-81. doi: 10.1007/s10661-006-1503-9. [PubMed:16897551]

20. Chowdhury KA, Debsarkar A, Chakrabarty S. Analysis of day time traffic noise level: A case study of Kolkata India. Int J Environ Sci Res. 2012;2(1):114-8.

21. UNEP/WHO. Urban air pollution in mega cities of the world. Oxford; Blackwell. 1992.

22. Central pollution control board of india. noise pollution (regulation and control) rules. 2000. Available from: http://cpcb.nic.in/ divisionsofheadoffice/pci2/noise_rules_2000.pdf.

23. Central Pollution Control Board of India. National ambient air quality standards. 2009. Available from: http://cpcb.nic.in/National_Ambient_Air_Quality_Standards.php.

24. Vidya Sagar T, Nageswara Rao G. Noise pollution levels in Visakhapatnam City (India). J Environ Sci Eng. 2006;48(2):139-42. [PubMed: 17913192] 
25. Banerjee D, Chakraborty SK, Bhattacharyya S, Gangopadhyay A. Evaluation and analysis of road traffic noise in Asansol: an industrial town of eastern India. Int J Environ Res Public Health. 2008;5(3):165-71. [PubMed:19139535]

26. Goswami S. Road traffic noise: A case study of Balasore town, Orissa, India. Int J Environ Res. 2009;3(2):309-18.

27. Hunashal RB, Patil YB. Assessment of noise pollution indices in the city of Kolhapur, India. Proc Soc Behav Sci. 2012;37:448-57.

28. Deshmukh DK, Deb MK, Tsai YI, Mkoma SL. Water soluble ions in PM2. 5 and PM1 aerosols in Durg city, Chhattisgarh, India. Aerosol Air Qual Res. 2011;11:696-708.

29. Pandey P, Patel DK, Khan AH, Barman SC, Murthy RC, Kisku GC. Temporal distribution of fine particulates (PM(2).(5):PM(1) (0)), potentially toxic metals, PAHs and Metal-bound carcinogenic risk in the population of Lucknow City, India. J Environ Sci Health A Tox Hazard Subst Environ Eng. 2013;48(7):730-45. doi: 10.1080/10934529.2013.744613. [PubMed: 23445416]

30. Tiwari S, Bisht DS, Srivastava AK, Gustafsson Ö. Simultaneous measurements of black carbon and PM2.5, CO, and NO x variability at a locally polluted urban location in India. Nat Hazards. 2015;75(1):813-29.

31. Kundu Chowdhury A, Debsarkar A, Chakrabarty S. Critical assessment of day time traffic noise level at curbside open-air microenvironment of Kolkata City, India. J Environ Health Sci Eng. 2015;13:65. doi:10.1186/s40201-015-0219-6. [PubMed: 26413307]

32. Weber S. Spatio-temporal covariation of urban particle num ber concentration and ambient noise. Atmospher Environ.
2009;43(34):5518-25. doi: 10.1016/j.atmosenv.2009.06.055.

33. Kaushal A, Rampal R. Seasonal variations in traffic flow rate versus Leq at major crossings of NH1A Jammu City, India. Indian J Appl Res. 2014;4(10):270-2.

34. Gupta A, Kumar R, Kumari KM, Srivastava SS. Measurement of $\mathrm{NO} 2, \mathrm{HNO} 3, \mathrm{NH} 3$ and $\mathrm{SO} 2$ and related particulate matter at a rural site in Rampur, India. Atmospher Environ. 2003;37(34):4837-46. doi:10.1016/j.atmosenv.2003.07.008.

35. Ghude SD, Fadnavis S, Beig G, Polade SD, van der A RJ. Detection of surface emission hot spots, trends, and seasonal cycle from satellite-retrieved NO2over India. J Geophys Res. 2008;113(D20). doi:10.1029/2007jd009615.

36. Kulshrestha A, Satsangi PG, Masih J, Taneja A. Metal concentration of $\operatorname{PM}(2.5)$ and $\operatorname{PM}(10)$ particles and seasonal variations in urban and rural environment of Agra, India. Sci Total Environ. 2009;407(24):6196-204. doi: 10.1016/j.scitotenv.2009.08.050. [PubMed: 19793609]

37. Anfosso-LédéE F, Pichaud Y. Temperature effect on tyreroad noise. Appl Acoustics. 2007;68(1):1-16. doi: 10.1016/j.apacoust.2006.06.001

38. Bueno M, Luong J, Viñuela U, Terán F, Paje SE. Pavement temperature influence on close proximity tire/road noise. Appl Acoustics. 2011;72(11):829-35. doi:10.1016/j.apacoust.2011.05.005.

39. NZ Transport Agency. NZ Transport Agency research report 446 2011. Available from: http://www.nzta.govt.nz/assets/resources/ research/reports/446/docs/446.pdf. 